\title{
SC|A2
}

Edúcaçã̃o, Comunicação e Tecnologia

Atribuição BB CY 4.0

\section{O conhecimento para o mundo exponencial: As metodologias ativas na prática pedagógica}

\author{
Janaina Boniatti Bolson ${ }^{1}$ \\ Kelly Rodrigues ${ }^{2}$ \\ Marina Revello de Lima3
}

\section{Resumo}

O presente artigo tem como objetivo identificar diferentes metodologias ativas no contexto do ensino híbrido, em que são utilizadas tecnologias de informação e comunicação em sala de aula na interação do professor e aluno no mundo exponencial. Sabe-se que o conhecimento que os mesmos possuem acerca dessas tecnologias e o impacto no processo de ensino e aprendizagem são consideráveis e significantes. Foi realizado um estudo de cunho bibliográfico sobre ensino híbrido e aplicação de metodologias ativas em sala de aula, bem como de diferentes recursos tecnológicos que contribuem para o aprendizado. As gerações $\mathrm{Z}$ e alpha tem em seu cotidiano cada vez mais presente equipamentos tecnológicos em sala de aula, tais como: smartphone e notebook, e seu uso exploratório e seu uso é uma possibilidade de mantê-los motivados quanto à utilização dessas ferramentas em sala de aula. É importante o investimento das escolas para manter esses alunos e professores conectados. Através de fundamentação teórica, foi possível demonstrar que o ensino híbrido e metodologias ativas podem contribuir no processo de ensino e aprendizagem, uma vez que os alunos são envolvidos diretamente nos estudos e são instrumentalizados para administrar melhor seu tempo de estudo.

\section{Palavras-chave}

Tecnologia. Inovação. Metodologia ativa. Ensino Híbrido.

Recebido em: 30/11/2019

Aprovado em: 21/07/2020

\footnotetext{
${ }^{1}$ Doutora em Educação - UNISINOS- Universidade do Vale do Rio dos Sinos - Docente do Curso de Pedagogia da Faculdade Murialdo - FAMUR.

e-mail: janaina.bolson@famur.com.br

${ }^{2}$ Acadêmica do Curso de Pedagogia da Faculdade Murialdo - FAMUR.

e-mail: kelly.rodrigues@famur.com.br

${ }^{3}$ Acadêmica do Curso de Pedagogia da Faculdade Murialdo - FAMUR.

e-mail: marina.lima@famur.com.br
} 


\section{Knowledge for the exponential world: Active methodologies in pedagogical practice}

\section{Abstract}

This article aims to identify different active methodologies in the context of hybrid education, in which information and communication technologies are used in the classroom in the interaction of teacher and student in the exponential world. It is known that their knowledge about these technologies and the impact on the teaching and learning process are considerable and significant. A bibliographic study was carried out on hybrid teaching and the application of active methodologies in the classroom, as well as different technological resources that contribute to learning. The $\mathrm{Z}$ and alpha generations have, in their daily lives, increasingly present technological equipment in the classroom, such as: smartphone and notebook, and their exploratory use and use is a possibility to keep them motivated about the use of these tools in the classroom. class. It is important for schools to invest in keeping these students and teachers connected. Through theoretical foundation, it was possible to demonstrate that hybrid teaching and active methodologies can contribute to the teaching and learning process, since students are directly involved in studies and are instrumentalized to better manage their study time.

\section{Keywords}

Technology. Innovation. Active methodology. Hybrid Teaching. 


\section{Introdução}

A presente pesquisa tem como objetivo refletir e compreender diferentes metodologias ativas e ensino híbrido utilizados como ferramentas tecnológicas em um mundo exponencial no século XXI, com transformações rápidas que estão acontecendo na história da evolução humana. Novas formas de interagir, comunicar, informar, educar. Estamos vivendo uma realidade nunca imaginada, com incertezas e um futuro cheio de desafios.

Utilizar as metodologias ativas presentes em sala de aula possibilitando ferramentas tecnológicas podem interessar e despertar a curiosidade do aluno no processo de construção do conhecimento. Para isso, a capacitação e inclusão digital do profissional da educação são de suma importância porque o professor é a figura central da mediação do saber.

Temos que cuidar do professor, pois todas as mudanças só entram bem na escola se entrarem pelo professor, ele é a figura fundamental. Não há como substituir o professor. Ele é a tecnologia das tecnologias, e deve se portar como tal. (Apud ANDRADE, p.16)

As metodologias ativas estão presentes no meio educacional e, por conseguinte, no mundo exponencial em diferentes áreas de conhecimento, as quais inclusive vão ao encontro do que a BNCC (BRASIL, 2018) preconiza. De acordo com os conceitos sobre a tecnologia, relacionada à educação Niskier (1993) menciona algumas ideias como "uma mediação do encontro entre Ciência, Técnicas e Pedagogia." ou ainda como "um exercício crítico com utilização de instrumentos a serviço de um projeto pedagógico".

Segundo Brito \& Purificação (2011) a necessidade incentiva o impulso às criações tecnológicas, como o ábaco, instrumento utilizado por povos primitivos para auxiliar na contagem, considerado assim o primeiro computador. $\mathrm{Na}$ década de 40, em meio a segunda guerra mundial, os computadores modernos surgiram. Nos Estados Unidos, na década de 60, popularizou o microcomputador e este se tornou a principal ferramenta de trabalho. $\mathrm{Na}$ década de 90, a internet promoveu grandes mudanças nas esferas sociais e econômicas. Estas mudanças alteraram também a dinâmica escolar. Em 1970 
era percebido um movimento da informática na educação, tanto no setor administrativo quanto em sistemas eletrônicos de informação. E no Brasil a década de 80 foi marcada por grandes investimentos governamentais de informática na educação.

Em resumo Simão Neto (p.67) descreve o contexto:

Em seis ondas, são elas:primeira onda: logo e programação; segunda onda: informática básica; terceira onda: software educativo; quarta onda: internet; quinta onda: aprendizagem colaborativa; sexta onda: o que será? (SIMÃO NETO apud BRITO \& PURIFICAÇÃO, 2011, p.67).

Uma das competências gerais citadas na BNCC relacionada ao uso das tecnologias indica que devemos:

Compreender, utilizar e criar tecnologias digitais de informação e comunicação de forma crítica, significativa, reflexiva e ética nas diversas práticas sociais (incluindo as escolares) para se comunicar, acessar e disseminar informações, produzir conhecimentos, resolver problemas e exercer protagonismo e autoria na vida pessoal e coletiva (BNCC, 2018, p.9).

A revolução tecnológica vem modificando a forma de comunicação e relação entre os seres humanos, a qual criou um ambiente que é bastante natural e favorável às crianças e adolescentes de hoje: as gerações Z4 e Alpha5 - também conhecidos como screenagers um termo usado para descrever o ato de preferir ler, interagir com pessoas e com o mundo, utilizando-se de uma tela ou de algum equipamento disponível a ele.

O termo exponencial na era digital significa escala de resultado com o uso do mesmo ou de menos recurso que o habitual. Com base na Lei de Moore ${ }^{6}$ descobriu-se que um mesmo recurso é capaz de produzir o dobro do resultado em um período determinado. Tecnologias e empresas exponenciais são as que

\footnotetext{
4A Geração Z é a definição sociológica para a geração de pessoas nascida, em média, entre meados dos anos 1990 até o início do ano 2010.

5A geração Alpha é composta por crianças que desde muito pequenas, estão inseridas em um cotidiano rodeado pela tecnologia. Em pleno desenvolvimento, é precoce afirmar o que pensam, mas a tendência indica que sejam muito mais independentes que suas antecessoras, e com habilidade de adaptação a novas tecnologias.

${ }^{6}$ Até meados de 1965 não havia nenhuma previsão real sobre o futuro do hardware, quando Gordon E. Moore fez sua profecia, na qual o número de transistores dos chips teria um aumento de 100\%, pelo mesmo custo, a cada período de 18 meses. Essa profecia tornou-se realidade e acabou ganhando o nome de Lei de Moore
} 
produzem mais com menos recurso. Essa é a realidade das diferentes gerações que se utilizam desses recursos digitais para a aprendizagem. Em sala de aula é uma possibilidade ímpar de aproximar e despertar a curiosidade da criança sobre os mais diversos conhecimentos, das mais diversas áreas. Esta revolução não trouxe apenas novas possibilidades ao professor, mas também aos ambientes corporativos e âmbito familiar. Trouxe acesso a uma abundância de informações que estão disponíveis nas mais variadas mídias e canais, favorecendo a curiosidade, despertando a exploração e a pesquisa, bem como a autonomia digital dessas gerações.

Pierre Lévy, filósofo francês da cultura virtual contemporânea, já em 1996, chamava atenção para o fato de que as tecnologias fazem parte de nossa cultura e devem ser potencializadas. A internet trouxe para a prática pedagógica novas formas de ensino - a colaboração, a comunicação e a imersão são termos novos que já fazem parte do contexto de ensino e geram o que Pierry Levy (1996) chamou de inteligência coletiva. Moran aborda bem essa questão ao afirmar que,

Do ponto de vista metodológico, o educador precisa aprender a
equilibrar processos de organização e de "provocação" na sala
de aula. Uma das dimensões fundamentais do ato de educar é
ajudar a encontrar uma lógica dentro do caos de informações
que temos, organizá-las numa síntese coerente, mesmo que
momentânea, compreendê-las. Compreender é organizar,
sistematizar, comparar, avaliar, contextualizar. Uma segunda
dimensão pedagógica procura questionar essa compreensão,
criar uma tensão para superá-la, para modificá-la, para avançar
para novas sínteses, outros momentos e formas de
compreensão. Para isso, o professor precisa questionar, criar
tensões produtivas e provocar o nível da compreensão existente
(MORAN, 2009, p.101-111). A metodologia utilizada para desenvolver este artigo deu-se em forma de pesquisa bibliográfica, pautada em uma análise qualitativa dos principais conceitos, pertinentes ao objeto de estudo. Foram efetuadas pesquisas em artigos relacionados à temática nas plataformas virtuais Google Acadêmico e Scielo. A produção textual elaborada pelos autores e a discussão em relação ao tema foram estritamente feitas no editor de texto do Google Drive, de forma assíncrona. 


\section{Mundo exponencial}

O mundo exponencial proporcional relaciona-se a tecnologias inovadoras como inteligência artificial, futurismo, painéis solares, veículos híbridos, realidade aumentada e robótica entre outras. No século XXI, as crianças têm acesso e oportunidades de estar próximo do que parecia estar tão distante. Principalmente a Geração Alpha, que são aquelas crianças que nasceram a partir do ano de 2010 e, devido ao contexto social atual, estão voltadas para a tecnologia e podem ser, mesmo com pouca idade, influenciadoras digitais (CARTER, 2016).

Uma organização exponencial como aquela "cujo impacto (ou resultado) é pelo menos dez vezes maior se comparada com seus pares tradicionais, devido ao uso de novas metodologias organizacionais que alavancam (e também são alavancadas) pelas tecnologias exponenciais aceleradas, ou seja, desmontam o conceito físico e são construídas com base em tecnologia (DIAMANDIS, 2016).

Podemos observar que há a convivência de múltiplas gerações em sala de aula, pois antigamente nós tínhamos como fonte de consulta a "Barsa" hoje temos inúmeros sites que proporcionam acesso às mais diversas informações de modo rápido.Quando olhamos para o mundo nos surpreendemos, pois vivemos em um mundo colaborativo, tendo acesso a pesquisa.

Hoje as crianças têm em mãos aparelhos atualizados com a capacidade de aprendizados realizando diversas tarefas como tv ligada, conectados no instagram e podcast no ouvido, audiobook de vídeos aulas, os quais constituem-se em evidências dos modos de ser e estar no mundo no século XXI. As informações hoje se propagam rapidamente, as tecnologias estão cada vez mais avançadas, logo abaixo temos informações de porcentagens que mostra o percentual de pessoas conectadas à internet no mundo e no Brasil com acesso em diferentes informações, compras, mídias sociais e comunicação. 

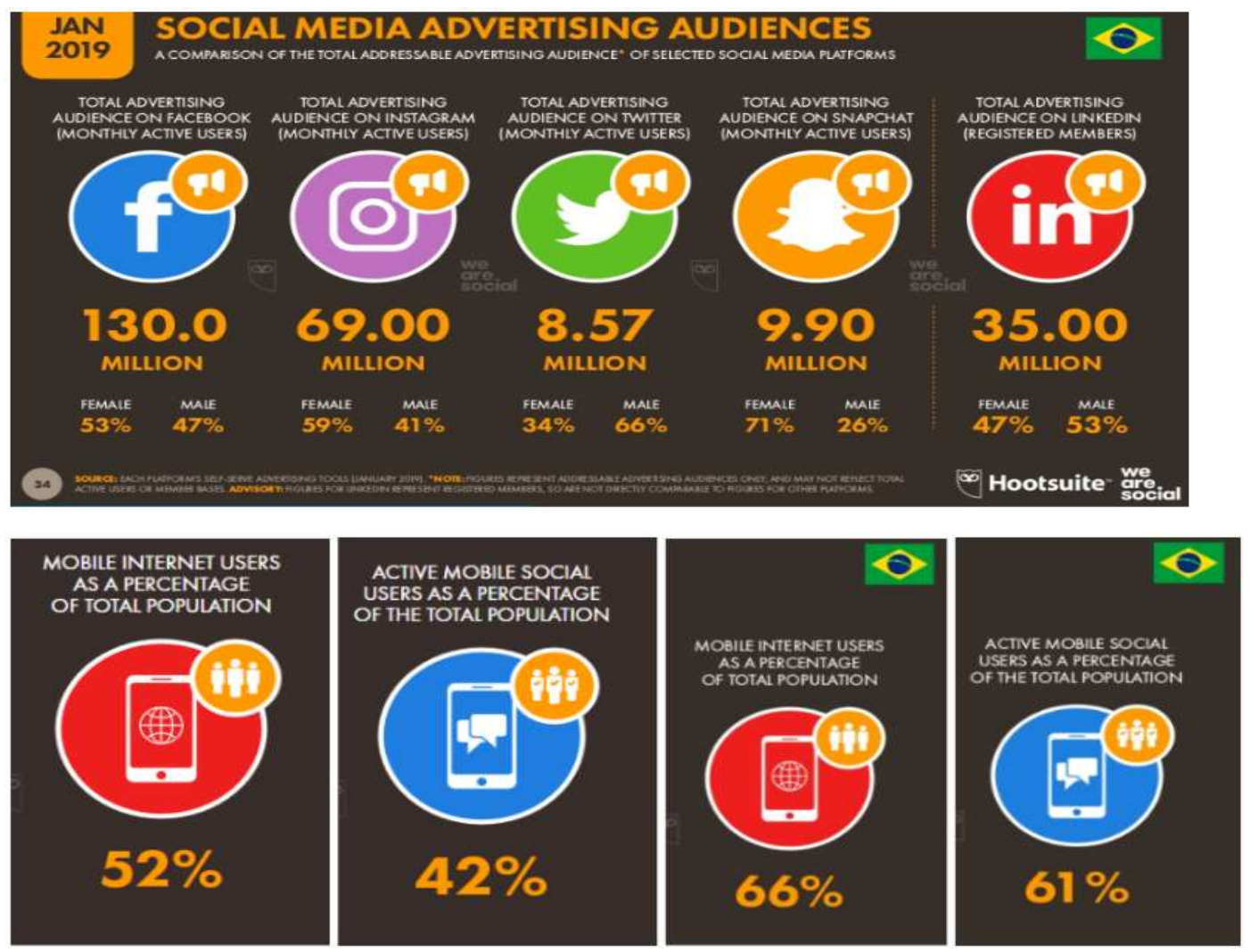

Fonte: https://wearesocial.com

\section{Ensino híbrido}

A partir de mudanças tecnológicas constantes, em todos os setores de nossas vidas, podemos constatar que estas exercem influências de como ser e estar no mundo. Strieder (2002, p.11), destaca que "o mundo vive em constante e cada vez mais rápido processo de mudanças. O cenário humano e econômico requer formas educacionais mais flexíveis para também formas de trabalho e carreiras flexíveis".

A educação híbrida é uma forma de ensino que traz o melhor de online e offline. Esta metodologia é o elo entre os dois modelos de aprendizagem: o presencial e o online. Ou seja, parte do processo ocorre em sala de aula, em que os alunos interagem entre si trocando experiências e vivências. A parte online vem através de métodos digitais para trabalhar a autonomia do aluno, no processo de aprendizagem. 


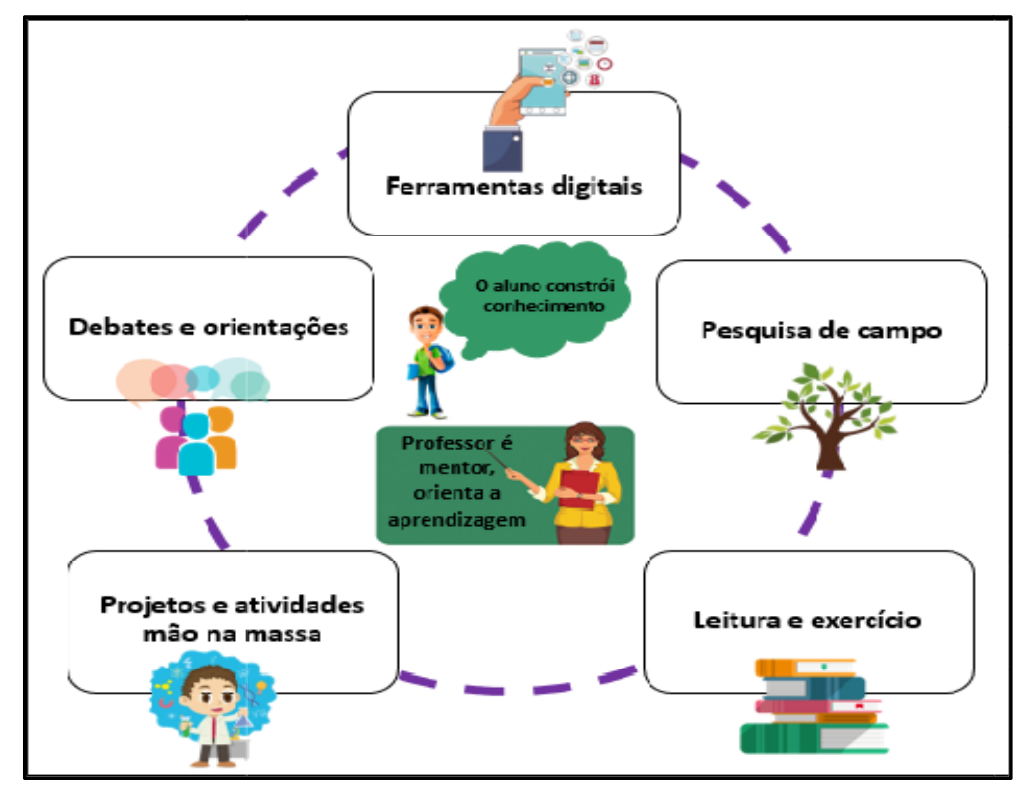

Figura 1- Ciclo. Elaborado pelas autoras (2019).

Ferramentas digitais: Tudo que nos possibilita uma interação entre o homem e a tecnologia com o uso de vários dispositivos: tablets, celular, smartphone, Iphone, Ipod entre outros aparelhos tecnológicos. Tanto para uso profissional ou educacional facilitando a comunicação global.

Pesquisa de campo: São etapas da metodologia científica de pesquisa que remetem à observação, coleta, análise e interpretação de fatos e fenômenos que ocorrem dentro de seus nichos, cenários e ambientes naturais de vivência.

Leitura e exercício: $O$ ato da leitura nos favorece para aprendizagem e construção desenvolvida no humano, além, de nos proporcionar o aprendizado de conteúdo específicos, vem aprimorando a escrita. O contato com os livros ajuda ainda a formular e organizar uma linha de pensamento. Dessa forma, a apreciação de uma obra literária é uma aliada na hora de elaborar uma pesquisa científica ou artigo.

Projetos de atividades mão na massa: A vivência pôr a mão na massa, tem sido tão prazerosa e desafiadora nas escolas do mundo inteiro, ganha força um movimento que valoriza a prática e a experimentação. 
Debates e orientações: No ensino híbrido existe o estímulo ao debate de ideias, à construção colaborativa do conhecimento e à movimentação por espaços diferentes com colegas diferentes com orientação do professor proporcionando o protagonismo ao aluno. Isso permite que os alunos possam aprimorar, desde cedo, as habilidades sociais que serão tão importantes na vida adulta.

\section{Diferentes metodologias ativas}

O ensino híbrido (blended learning, em inglês) combina atividades com e sem a ação do professor com o uso de tecnologia. Dessa forma, possibilita que o aluno estude sozinho, com o apoio da internet, e em sala de aula, seja em grupo ou com o professor.

Dessa forma, o ensino híbrido abre um espaço para o pensamento crítico, afinal os estudantes têm a oportunidade de compreender os assuntos de maneira mais aprofundada e, ainda, agregar questões e curiosidades aos encontros presenciais.

Neste caso, vale destacar a existência de vários benefícios tanto para a comunidade acadêmica quanto para a instituição de ensino com a utilização das metodologias ativas. Nessa direção, os alunos desenvolvem habilidades positivas que podem possibilitar um ser humano pesquisador, pois: adquirem maior autonomia;desenvolvem confiança;passam a enxergar o aprendizado como algo tranqüilo; tornam-se aptos a resolver problemas;formam-se profissionais mais qualificados e valorizados e apresentam-se como protagonistas do seu aprendizado.

Segundo Dewey (1974) a utilização de desafios educacionais no formato de problemas mostra-se coerente com o modo como as pessoas, naturalmente, aprendem. Segundo esse autor, a educação deve voltar-se à vivência de experiências ao invés da transmissão de temas abstratos. 
A metodologia ativa enfatiza a importância de vivenciar as experiências para o aprendizado, de modo que a vivência traga a eficiência do que chamamos de aprender na prática no modo colaborativo. Na presente pesquisa abordamos as mais atuais que se faz necessário da tecnologia como: (Gamificação na educação), (Aprendizagem Baseada Em Projetos), (Pensar / Par / Compartilhar) e (Pensamento de Projeto) proporcionando a flexibilidade e a interação com outro, proporcionando ao indivíduo o enriquecimento do conhecimento e para isso é de grande importância algumas ações como citado na BNCC - Base Nacional Comum Curricular (BRASIL, 2018) documento facilitador com a finalidade de nortear aprendizagem nas mais diversas áreas de conhecimento e níveis e modalidades de ensino da nação. Nas questões referentes à associação das tecnologias nos processos de ensino-aprendizagem, o documento anuncia para a importância de:

selecionar, produzir, aplicar e avaliar recursos didáticos e tecnológicos para apoiar o processo de ensinar e aprender;criar e disponibilizar materiais de orientação para os professores, bem como manter processos permanentes de formação docente que possibilitem contínuo aperfeiçoamento dos processos de ensino e aprendizagem;manter processos contínuos de aprendizagem sobre gestão pedagógica e curricular para os demais educadores, no âmbito das escolas e sistemas de ensino (BRASIL, 2018, p.9).

Hoje, a escola que não souber trabalhar com diferentes metodologias ativas como essas citada na pesquisa, entre outras metodologias de aprendizagem, necessita repensar algumas práticas, pois pode vir a ser percebida como ultrapassada e que pouco investe em processos permanentes de qualificação de seus profissionais, e também de seus aspectos estruturais. A aula expositiva, somente, não atende mais às demandas das novas gerações.

\section{Gamificação na educação ou Gamification In Education - Effective Learning For Education}

Também conhecida como "gamificação', veio para o meio educacional com o propósito de criar dinâmicas, para se atingir determinados objetivos. Não se remete a usarmos jogos prontos, mas sim utilizarmos recursos que promovam a interatividade, resolução de problemas, alcance de objetivos, linguagem tecnológica e trabalho em equipe. 
Existem muitas ferramentas para gamificação. Alguns deles são baseados na Web (serviços em nuvem) e não requerem a instalação de software especial e permitem acesso a qualquer momento e em qualquer local.

Criação de conteúdo e atividades educacionais para gamificação: O conteúdo educacional deve ser interativo, envolvente e rico em elementos multimídia. As atividades de treinamento devem ser desenvolvidas sob medida para os objetivos de aprendizagem e permitir: múltiplas apresentações, já que as atividades aprimoram suas habilidades; viabilidade, pois precisam ser adaptados e adaptados ao potencial e aos níveis de habilidade dos aluno; aumentar o nível de dificuldade do acesso às informações correspondendo aos seus conhecimentos e habilidades recém-adquiridos;múltiplos caminhos para que construam suas próprias estratégias, que é uma das principais características da aprendizagem ativa.

Segundo Zichermann e Cunningham (2011), a gamificação explora os níveis de engajamentos do indivíduo para resolução de problemas.

\section{Aprendizagem Baseada Em Projetos ou Project Based Learning}

O Project Based Learning é um método moderno, utilizado em diversas etapas de aprendizagem - desde o ensino infantil até o universitário. Porém esse conceito também pode ser bem aproveitado na educação corporativa, proporcionando uma nova experiência para os alunos: um aprendizado mais prático e proativo.

Este método de aprendizagem nos leva a uma aprendizagem autônoma, envolvendo projetos bem fundamentados sobre determinados conteúdos, para que desenvolvam o pensamento crítico, comunicação e a colaboração.

Enquanto no método tradicional e até em outros mais atuais, como o EAD, o estudante passa a maior parte do tempo assistindo as aulas, no PBL ele é quem deve correr atrás de pesquisar, compreender, apresentar e aplicar o 
conhecimento adquirido. Desta forma, não há como o funcionário mal prestar a atenção nos conteúdos e acabar chutando todas as questões nos testes de desempenho. Como o aprendizado depende do seu movimento, o estudante terá que ser mais proativo e interagir com o treinamento para atingir os resultados desejados das atividades.

Vasconcelos (2009) menciona a vantagem de se trabalhar com projetos ressaltando o despertar a curiosidade "atiçada" dos alunos, ao se envolver nessa estratégia de ensino, o que promove a apropriação de conteúdos previstos e não previstos porque o aluno sempre busca além quando tem interesse.

\section{Pensar / Compartilhar e Socializar ou Think / Pair / Share}

Idealizado por Frank Lyman, traduzido como pensar, compartilhar e socializar, vem com a proposta de interação e diálogo entre a turma, com o objetivo de que cada um mostre suas ideias e opiniões, em cima da leitura que realizaram.

O mundo mudou, disso não temos dúvidas. As tecnologias digitais programam uma nova interface para o planeta. Para onde olhamos, nos deparamos com a automação, e muitos itens hoje realizam tarefas que antes levaríamos horas, talvez dias para realizar. Tudo isso modificou vários cenários, inclusive o da educação. Mas não é novidade! Temos estratégias e métodos que estão sendo elaborados desde a década de 1970, mas, hoje, ganham um UPGRADE com as tecnologias digitais.

Essa estratégia exige as seguintes situações:

1. Leitura prévia.

2. Construção objetiva de um texto pessoal.

3. Diálogo e apresentação de ideias a um colega.

4. Apresentação geral de ideias para toda a turma.

Isso promove uma situação interessante, pois, além da leitura, essencial em qualquer método ou estratégia, possibilita a integração e o diálogo com outro colega. Aprendemos juntos, percebemos o caminho que o colega trilhou com 
base em seus conhecimentos anteriores e no entendimento de sua leitura, o que amplia nossa percepção e nos mantém seguros para continuar a produzir nossas respostas. Além disso, oferece igual oportunidade de fala nas apresentações socializadas, em que todos os alunos precisam falar, mesmo que por um ou dois minutos. Geralmente, o que vemos é um aluno ou outro apresentando suas ideias, mas, quando damos condições a todos, fazemos com que percebam que a resposta ou as ideias não estão distantes daquilo que seus colegas também apresentam.

O TPS, ou PCS, se mostra uma estratégia eficaz para a realização e entendimento das leituras, além de promover todos os alunos, garantindo a equidade.

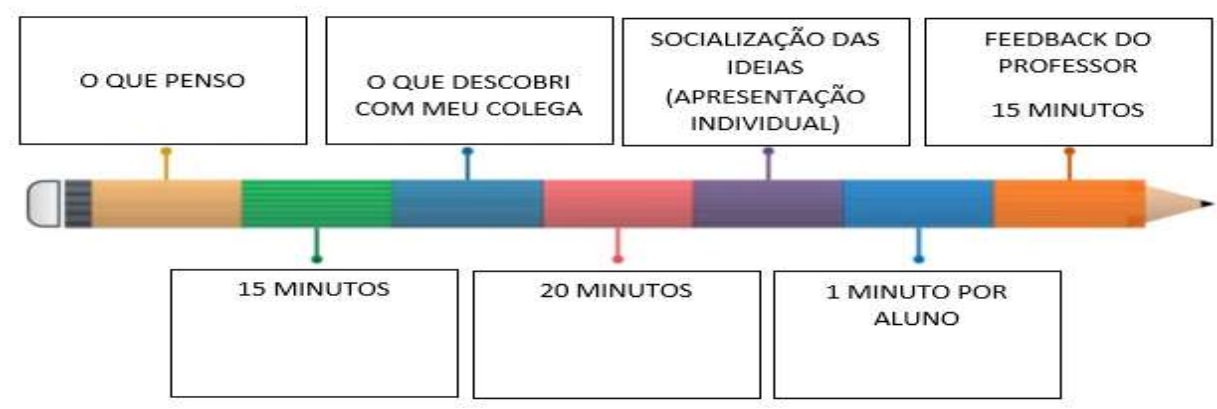

Figura 2 - Ciclo produzido pelas autoras do artigo

Hegazy e Ghorab (2014) fortalecem o entendimento de que o compartilhamento e a socialização geram pelo menos seis níveis de impacto: eficiência; eficácia; inovação; adaptabilidade; aprendizagem; e satisfação.

\section{Pensamento de Projeto ou Design Thinking}

É o método de aprender com empatia e criatividade, com a descoberta, interpretação, ideação, experimentação, evolução. Podendo organizar seus próprios pensamentos, ideias, para que possa transmiti-los. 


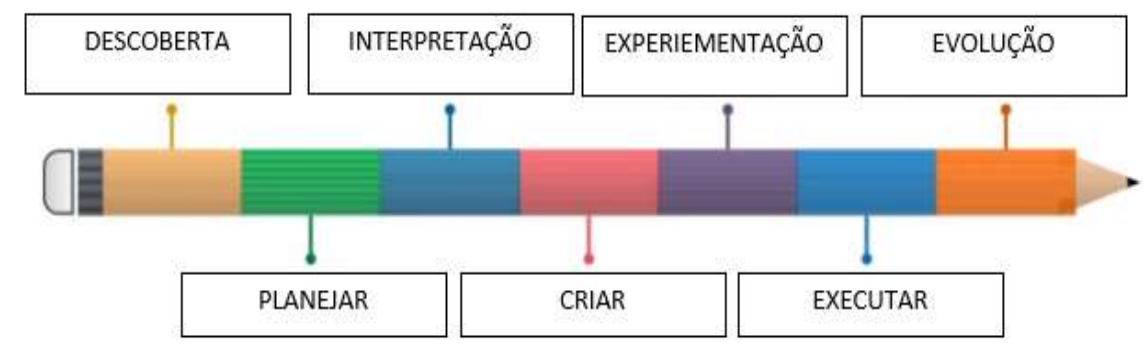

Figura 3 - Abordagens na aprendizagem

Não existe uma receita pronta, mas, alguns caminhos para abordagem, conforme a ilustração abaixo pode ser seguida para uma aprendizagem qualificada:

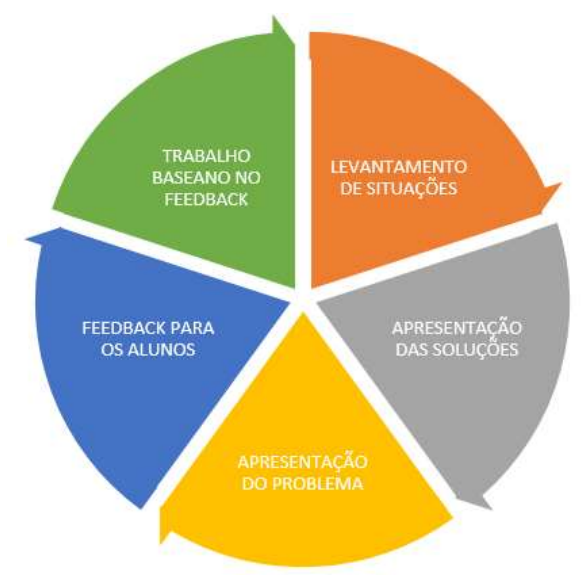

Figura 4 - Etapas na interação

Para enriquecer as etapas e possibilitar interação, é possível utilizar alguns softwares gratuitos, como:

Mind Node: programa muito simples e prático para ser utilizado ao dia a dia. Ele ajuda a visualizar melhor as ideias.

Free mind: é um software livre para criação de mapa mental, ele é simples e objetivo, disponível para usuários Windows e Linux.

Ree Plane: outro programa simples, compatível com Windows e Linux, que facilita a organização das ideias. 
Coggle: software online, permite mais que uma pessoa trabalhe com o mesmo mapa mental. Não é preciso fazer download do programa, o que permite trabalhar no projeto de diferentes plataformas (como pelo celular em casa e no computador do laboratório da escola).

O presente artigo destaca as vantagens e potencializar as metodologias ativas que são modelos de ensino, que visam o desenvolver e a autonomia e a participação dos alunos de forma integral, estimulando assim as diferentes

formas do aprendizado, possibilitando uma aula muito mais dinâmicas e visando trabalhar as competências do século XXI. Desta forma, as práticas pedagógicas são beneficiadas e por conseguinte o processo educativo.

\section{Conclusão}

Percebe-seque as metodologias ativas e o ensino híbrido estão cada vez mais ocupando um espaço nas instituições escolares porque através da observação da realidade, passa a ser problematizada de maneira dinâmica e reflexiva.Faz-se importante pensar em uma educação voltada para essas gerações $Z$ e Alpha, pois podemos gerar uma mais educação transformadora com aprendizagem qualificada, que tem por missão de colaborar para o desenvolvimento do ser humano com mais consciência, autonomia, responsabilidade social e protagonismo.

Diante da pesquisa bibliográfica é possível permanecer a "sala de aula" se o projeto educativo é inovador, - currículo, gestão competente, metodologias ativas, ambientes físicos e digitais atraentes - a escola tem que proporcionar aos professores aprimoramento e formação continuada.Temos consciência, no Brasil, de inúmeras deficiências históricas, estruturais, mas os desafios são muito maiores porque insistimos em atualizar-nos dentro de modelos previsíveis, industriais, em caixinhas. Os tempos são outros no século XXI, os espaços precisam ser revistos e isso é complexo, necessário e um pouco assustador para as antigas gerações, pois não temos modelos prévios bemsucedidos para aprender. Todos nós estamos sendo pressionados para mudar sem muito tempo para testar. Por isso, é importante que cada escola defina um 
plano estratégico de como fará essas suas mudanças dentro de suas realidades, muitas vezes o professor já propõe em sala de aula, mas não tem o conhecimento de que está utilizando uma metodologia ativa.

Se faz necessário mudanças de forma pontual, inicialmente, proporcionado aos professores, gestores e alunos ferramentas, os quais estão mais motivados e têm experiências em integrar o presencial e o virtual. Podemos aprender e buscar conhecimento com os que estão mais avançados e compartilhar este aprendizado,atividades, soluções. O pensar mais estruturalmente exige mudanças a longo prazo e se faz importante, portanto capacitar coordenadores, professores e alunos para atuar com metodologias ativas, com currículos mais flexíveis, com inversão de processos (primeiro, atividades online e, depois, atividades em sala de aula) acaba por ser imprescindível. Ao realizar mudanças incrementais, aos poucos vai introduzindo ou, quando possível, mudanças mais significativas, disruptivas, que mudem os modelos estabelecidos. 


\section{Referências}

ANDRADE, Ana Paula Rocha de. O Uso das Tecnologias na Educação: Computador e Internet. Computador e Internet, Universidade de Brasília e Universidade Estadual de Goias, ano 2011, p. 1-22, 2011.

CARTER, Christine. The complete guide to generation alpha, the children of millennials. Washington: Forbes, 21 dez. 2016. p. 1-3.

DEWEY, J. A escola e a sociedade; a criança e o currículo. Lisboa: Relógio d'Água; 2002.

DIAMANDIS, P.H, \& KOTLER, S. (2016). Oportunidades exponenciais. HSM.HEGAZY, F. M.; GHORAB, K. E. The influence of knowledge management on organizational business processes' and employees' benefits. International Journalof Business and Social Science, v.5, n.1, p.148-172, jan. 2014.

JOHNSON, D.W. e JOHNSON, R.T. Instructional GO alstructure: cooperative, competitive or individualistic. Review of Educational Research, v. 44, p. 213240, 1974.

LÉVY, P. Cibercutura. 2.ed. São Paulo: Editora 34, 2000.

MORAN, J. M. A educação que desejamos: novos desafios e como chegar lá. Campinas: Editora Papirus. - SP, 2007.

MORAN, J. M. Ensino e aprendizagem inovadores com tecnologia. In http: www.eca.usp.br/moran/inov.html>.Acesso: 05 set. 2019.

VASCONCELLOS, C. dos S. Currículo: a atividade humana como princípio educativo. São Paulo: Libertad, 2009.

ZICHERMANN, Gabe. Gamification by design ISBN 1449397670, 150 pages O’Reilly, 2011 